\title{
Observations on the Storage, Viability, and Ultrastructure of Mycoplasmas
}

\author{
C. T. K.-H. Stadtländer
}

Greenville Hospital System/Clemson University Biomedical Cooperative and Department of Microbiology, Clemson University, Clemson, SC 29634

Mycoplasmas (class: Mollicutes) are the smallest known free-living and self-replicating prokaryotes that are distinct from Gram-negative and Gram-positive bacteria by the lack of a rigid cell wall. They often appear pleomorphic on electron micrographs, are osmotic fragile, and belong to one of the most nutritionally fastidious groups of microorganisms.

The current study was undertaken to investigate the effects of several factors involved in storage and survival of mycoplasmas subjected to freezing and thawing. These microorganisms are excellent study objects in this regard because they can easily be injured due to the lack of a protective cell wall. Studies about storage and viability of mycoplasmas are important because they extend our knowledge about the biology and morphology of these microorganisms and they can lead to improvements of our currently used cryopreservation techniques. Only a few publications exist describing the effects of freezing on mycoplasmas. Unfortunately, these studies were mainly directed at investigating mycoplasmas based on viable cell counts without considering the effects of cryopreservation on the ultrastructure of the cells [1,2]. It was attempted in the current study to fill this gap and perform both a colony count investigation and an ultrastructural analysis.

Investigations were performed with Mycoplasma (M.) fermentans and $M$. salivarium. Stock cultures of mycoplasmas were prepared in the following growth media: SP-4, Hayflick, Friis, and $\mathrm{PH}$. Organisms were grown in batch cultures and harvested at late-log phase. Cultures were shaken to resolve mycoplasma aggregates, divided up into 1-ml portions, and then stored in cell concentrations of approximately $10^{8} \mathrm{CFU}$ at different temperatures with or without the addition of cryoprotective agents ( $15 \%$ glycerol or $15 \%$ serum). The samples were cooled either in a single step from $37^{\circ} \mathrm{C}$ directly to $4^{\circ} \mathrm{C}$, to $-20^{\circ} \mathrm{C}$, or to $-80^{\circ} \mathrm{C}$, or cooled in a combined series of steps covering $4^{\circ} \mathrm{C},-20^{\circ} \mathrm{C}$, and $-80^{\circ} \mathrm{C}$. Specimens were stored at each target temperature for up to 4 months. Thawing of mycoplasma cultures was accomplished by either reversing the freezing process (i.e., from $-80^{\circ} \mathrm{C}$ to $-20^{\circ} \mathrm{C}$ to $4^{\circ} \mathrm{C}$ to $37^{\circ} \mathrm{C}$ ) or by transferring them from the different temperature groups immediately to $37^{\circ} \mathrm{C}$. Survival of mycoplasmas in cultures was determined by using the colony count (CFU) method [3]. Ultrastructural changes on the mycoplasmas were investigated by using a Hitachi transmission electron microscope H-600-AB.

Mycoplasma survival after 4 months was best for both mycoplasma species at $-80^{\circ} \mathrm{C}$, followed by $-20^{\circ} \mathrm{C}$ and $4^{\circ} \mathrm{C}$. The greatest loss of viability (up to a $10^{5}$-fold reduction in CFU) was observed in cultures without cryoprotective agents. The addition of serum had the greatest protective effect on mycoplasmas grown in SP-4 medium, while the addition of glycerol had a beneficial effect on the survival of mycoplasmas stored in all of the four media. It turned out that a one-step cooling process (e.g., from $37^{\circ} \mathrm{C}$ to $-80^{\circ} \mathrm{C}$ ) was better than a multi-step cooling process (e.g., from $37^{\circ} \mathrm{C}$ first to $4^{\circ} \mathrm{C}$, then to $-20^{\circ} \mathrm{C}$, and then to $-80^{\circ} \mathrm{C}$ ). Furthermore, a single-step thawing process (e.g., from $-80^{\circ} \mathrm{C}$ to $37^{\circ} \mathrm{C}$ ) resulted in a better survival of mycoplasmas than a multi-step thawing 
process (e.g., from $-80^{\circ} \mathrm{C}$ to $-20^{\circ} \mathrm{C}$ to $4^{\circ} \mathrm{C}$ to $37^{\circ} \mathrm{C}$ ). The ultrastructual investigation revealed that all samples examined contained mycoplasma cells which had some form of degenerative changes. However, the degree of the ultrastructural alterations differed greatly and was dependent on the cryopreservation technique used. For example, the best preserved mycoplasma cells were observed in the glycerol group stored at $-80{ }^{\circ} \mathrm{C}$. Most damaged mycoplasma cells were found in the groups stored without cryoprotective agents and stored at either $4^{\circ} \mathrm{C}$ or at $-20^{\circ} \mathrm{C}$. The most prominent ultrastructural changes observed included damage to the cell membrane (mainly membrane ruptures), decrease in ribosome density, and appearance of cells with electron translucent cytoplasms (i.e., development of ghost cells).

This study contributes to the body of knowledge about storage and survival of mycoplasmas after freezing and thawing at different temperatures. It was shown that long-term storage of mycoplasmas is best at low temperature and that the addition of glycerol can effectively protect the organisms from freezing injury. These results corroborate findings by Raccach et al. [1]. The use of $15 \%$ serum appeared to be beneficial only in SP-4 medium. This medium contained the lowest percentage of a serum component (i.e., 17\% horse serum) prior to the addition of $15 \%$ serum as a cryoprotectant. It appears that the remaining media contained sufficient serum $(50 \%$ procine serum in Friis medium; 20\% horse serum in $\mathrm{PH}$ medium; and 20\% bovine serum in Hayflick medium) so that the supplementation with additional $15 \%$ of the corresponding serum did not give a greater cryoprotective effect. The different cooling and thawing processes resulted in different survival rates of the mycoplasmas. A one-step cooling process and a one-step thawing process increased the survival of mycoplasmas, while multi-step processes for freezing and thawing are not recommendable. Other investigators also observed that the faster the thawing the higher the number of survivors [1]. Finally, the electron microscopic investigation revealed that any kind of freezing procedure will cause injury to mycoplasma cells. However, the degree of cell damage can be significantly limited by freezing the microbes rapidly to $-80^{\circ} \mathrm{C}$ and later thawing them by using the one-step method.

In conclusion, this study showed that mycoplasmas are indeed very fragile when subjected to a freezing experiment. The death of bacteria undergoing freezing can be caused by numerous factors, including intracellular ice build-up, prolonged exposure to a culture medium that is altered by the presence of ice, and by starvation. Bank and Mazur [4] described that an optimal cooling velocity can significantly improve the survival of cells. The results of the present study confirm this observation. Future cryopreservation studies are highly warranted, in particular those investigations which help attributing cryofactors (e.g., ice-build-up, medium alteration, starvation) to particular freezing and thawing phases. It appears that mycoplasmas are excellent study objects for those proposed future studies.

\section{References}

[1] M. Raccach et al., Appl. Microbiol. 30 (1975) 167.

[2] P. M. Furr and D. Taylor-Robinson, J. Med. Microbiol. 31 (1990) 203.

[3] A. C. Albers and R. D. Fletcher, Appl. Environm. Microbiol. 43 (1982) 958.

[4] H. Bank and P. Mazur, J. Cell Biol. 57 (1973) 729.

[5] Current address of the author: University of St. Thomas, 1000 La Salle Avenue, TMH 100, Minneapolis, MN 55403; ctstadtlande@stthomas.edu or jmpstadtlander@aol.com. 